\title{
Seleção de esmaltes cerâmicos utilizando um delineamento experimental segundo Taguchi
}

\section{(Ceramic glaze obtaining and selection applying Taguchi experimental design)}

\author{
C. Lira, O. E. Alarcon \\ Universidade Federal de Santa Catarina - UFSC \\ Rua Osvaldo da Rocha Pires 247, Sambaqui, Florianópolis, SC 88051-145 \\ claudialirasc@yahoo.com.br
}

\begin{abstract}
Resumo
Para a obtenção de esmaltes com características adequadas a sua aplicação, é necessário definir, além da composição da frita base, a formulação da suspensão de esmalte e as condições de aplicação e queima. A influência de fatores como os aditivos utilizados e a temperatura de queima sobre as características do esmalte são muitas vezes desconhecidos. Este trabalho apresenta o método utilizado na condução dos testes de aplicação de esmaltes e os resultados obtidos para as características das superfícies esmaltadas. Foi analisada a influência de parâmetros da formulação do esmalte e temperatura de queima sobre as características de porosidade e dureza da superfície obtida. A utilização de um arranjo ortogonal de Taguchi auxiliou na escolha dos fatores e parâmetros dos testes de aplicação, definiu a sequiência de experimentos realizados e as propriedades medidas. As características avaliadas foram: a porosidade, a dureza ao risco, a dureza Mohs, a dureza Vickers e as características visuais. Após a realização dos experimentos foi possível identificar a formulação e os parâmetros que conferiram os melhores resultados quanto à aplicação pretendida para o esmalte.
\end{abstract}

Palavras-chave: esmalte cerâmico, Taguchi.

Abstract

Ceramic glaze with suitable characteristics can be obtained through selection of frit composition, glaze formulation and suitable application and firing parameters. However, most of time, the influence of factors like additives and firing temperature over glaze properties are unknown. This work presents the experimental design used for glaze application tests and resulting glazed surface characteristics. The influence of glaze formulation and firing temperature parameters over porosity and surface hardness was analyzed. A Taguchi orthogonal array provided support on conducting application tests and on analysis of glaze properties. The properties that were analyzed were: porosity, scratch hardness, Mohs hardness, Vickers hardness and visual characteristics. After this analysis the most suitable parameters for glaze obtaining were selected.

Keywords: ceramic glaze, Taguchi.

\section{INTRODUÇÃO}

A obtenção de esmaltes com características adequadas à sua aplicação compreende não só a determinação da composição e obtenção de fritas, mas requer a investigação dos parâmetros para formulação da suspensão a ser aplicada e para o tratamento térmico da superfície esmaltada. A microestrutura da camada esmaltada: fases cristalinas, fase vítrea, distribuição de fases e porosidade irá depender dos parâmetros selecionados para o processo de obtenção, como: temperatura de queima, composição da frita, formulação do esmalte, entre outros. E, por sua vez, a microestrutura obtida irá determinar as características de dureza, resistência química, resistência a manchas e estética da superfície esmaltada. A investigação destes parâmetros demanda a realização de experimentos variando-se os fatores investigados, dentro de certos níveis, avaliando-se, então, quais valores apresentaram os melhores resultados. A condução destes experimentos deve ser planejada de modo a permitir a identificação de efeitos relativos à variação dos parâmetros, através de avaliação objetiva e de acordo com determinada margem de segurança.

No método tradicional de planejamento experimental, segundo um arranjo fatorial completo, cada fator varia entre os níveis de forma independente em cada experimento, enquanto os demais permanecem constantes. Este método se mostra adequado para a investigação de poucos fatores e poucos níveis de variação, mas demanda uma enorme quantidade de experimentos quando se deseja investigar uma maior quantidade de fatores e níveis. A ferramenta estatística Taguchi oferece uma forma sistemática e eficiente para otimizar o delineamento experimental, permitindo a redução do número de experimentos em relação ao arranjo fatorial completo, para determinados níveis de confiabilidade [1]. Este método constitui uma ferramenta para planejar, conduzir e avaliar 
estatisticamente experimentos, utilizando arranjos ortogonais para a sequiência de fatores a serem testados e analisados, com respeito a sua influência em determinadas características do material [2].

A partir da investigação realizada em trabalhos anteriores $[3,4]$, foram selecionadas as composições a serem testadas na aplicação como esmaltes sobre o suporte cerâmico.

Visando uma análise objetiva da influência dos diversos fatores sobre as características da superfície esmaltada, utilizou-se um delineamento experimental pelo método de Taguchi. Os experimentos realizados têm o objetivo de avaliar a influência de fatores relativos à formulação e queima do esmalte nas características visuais, de dureza e porosidade da camada esmaltada. Neste sentido, serão analisados os fatores: temperatura de queima, composição da frita base e percentual de aditivos na formulação do esmalte (alumina e frita transparente).

Com base na análise dos experimentos e seus resultados pretende-se orientar a escolha de parâmetros de produção, que permitam obter um esmalte cerâmico que garanta as seguintes características para o produto final:

- superfície lisa e sem defeitos;

- alta resistência à abrasão;

- alta resistência ao manchamento.

\section{MATERIAIS E MÉTODOS}

Foram testadas duas fritas nos experimentos, denominadas: frita base $\mathrm{Me}$ frita base $\mathrm{C}$. A frita $\mathrm{M}$ tem composição determinada no sistema $\mathrm{MgO}-\mathrm{Al}_{2} \mathrm{O}_{3}-\mathrm{SiO}_{2}$ e a frita $\mathrm{C}$ tem composição determinada no sistema $\mathrm{CaO}-\mathrm{Al}_{2} \mathrm{O}_{3}-\mathrm{SiO}_{2}$. As fritas selecionadas são bastante refratárias, sendo indicadas para aplicação sobre grêsporcelanato, utilizando temperaturas de queima entre 1180 e $1200{ }^{\circ} \mathrm{C}$. As fritas foram obtidas a partir da mistura de óxidos no percentual correspondente, seguindo-se a fusão isotérmica da mistura à $1500{ }^{\circ} \mathrm{C}$ por $30 \mathrm{~min}$. e resfriamento em água. $\mathrm{Na}$ aplicação dos esmaltes foram utilizados suportes de grêsporcelanato, para monoqueima sem engobe.

Para a formulação do esmalte foram utilizados os seguintes componentes e respectivos percentuais em peso: $85 \%$ Frita base + aditivos; $15 \%$ Caulim; $0,13 \%$ CMC e $0,10 \%$ TPF. Os componentes sólidos foram utilizados em suspensão com $40 \%$ de água. Os componentes foram misturados e reduzidos em moinho rápido de laboratório por 5 minutos (resíduo em malha $45 \mu \mathrm{m}=4 \%$ ). Então, aplicou-se o esmalte sobre o suporte cerâmico previamente umedecido, utilizandose um binil, com regulagem para espessura da camada de aproximadamente $0,7 \mathrm{~mm}$.

As amostras esmaltadas foram secas em estufa a $110{ }^{\circ} \mathrm{C}$ por 24 horas e, então, submetidas à queima em forno mufla. Os ciclos de queima utilizaram taxa de aquecimento de $20{ }^{\circ} \mathrm{C} / \mathrm{min}$, com patamares de $5 \mathrm{~min}$ à $850{ }^{\circ} \mathrm{C}$ para desgaseificação do suporte, $15 \mathrm{~min}$. à temperatura de $1100^{\circ} \mathrm{C}$ e 5 min. à temperatura máxima. As temperaturas máximas foram estabelecidas em 1180 e $1200{ }^{\circ} \mathrm{C}$.

A partir da definição do problema e determinação dos objetivos descritos na introdução, procedeu-se ao delineamento experimental, segundo Taguchi, projetando-se as características medidas, fatores, níveis e arranjos utilizados nos experimentos.

\section{Seleção das Características Medidas e Sistema de Medição}

Serão efetuadas medidas das seguintes características:

- porosidade: determinação gráfica por contagem de pontos sobre micrografia da camada esmaltada polida. Amostragem: seis micrografias (Ampliação 200X) da seção transversal e seis micrografias da superfície para cada formulação;

- dureza ao risco: ensaios efetuados em esclerômetro com carga de $2 \mathrm{~N}$ e velocidade de riscamento de $1 \mathrm{~mm} / \mathrm{s}$. O indentador utilizado é um indentador Vickers, piramidal com ponta de diamante. O esclerômetro utilizado foi fabricado no Laboratório de Materiais (LabMat) da Universidade Federal de Santa Catarina, cujo erro relativo à estabilidade da carga situa-se em $\pm 5 \%$ (componente normal). Amostragem: dois riscos sobre superfície polida para cada formulação, com três medidas por risco;

- dureza Vickers: ensaios efetuados em microdurômetro sobre a superfície esmaltada polida, utilizando carga de $2 \mathrm{Ne}$ tempo $=15$ s. Amostragem: cinco medidas sobre superfície polida para cada formulação. A média é calculada descontandose o maior e o menor valor.

- dureza Mohs: ensaios efetuados segundo a norma NBR 13818/ 97 - Anexo V [5]. Amostragem: cinco peças para cada formulação.

Adicionalmente às características medidas, serão avaliadas as características de aspecto da superfície: brilho, textura, aderência e empeno. Entretanto estas serão avaliadas apenas visualmente, fornecendo base qualitativa para selecionar os parâmetros com resultados desejáveis nas características estéticas da peça esmaltada.

\section{Determinação dos fatores a serem investigados}

Pretende-se avaliar a influência dos seguintes fatores sobre as características da camada esmaltada:

- Fator A: Frita base para a formulação do esmalte. Pretendese verificar qual das composições de fritas selecionadas apresenta as melhores características para a camada esmaltada.

- Fator B: Adição de frita transparente. Pretende-se verificar se a adição de uma frita transparente comercial, que não apresenta cristalização, resulta em maior brilho e menor porosidade da camada esmaltada.

- Fator C: Temperatura de queima. Pretende-se verificar se a temperatura de queima apresenta influência na dureza e na porosidade da camada esmaltada.

- Fator D: Adição de alumina $\left(\mathrm{Al}_{2} \mathrm{O}_{3}\right)$. Pretende-se verificar se a adição de partículas de uma fase cristalina de alta dureza (dureza Mohs da alumina $=9$ ) resulta em um aumento da dureza da camada esmaltada.

\section{Seleção dos níveis para os fatores investigados}

Para cada fator foram selecionados dois níveis de variação, apresentados na Tabela I. Estes níveis foram escolhidos tomando como base os parâmetros comumente utilizados em formulações comerciais. 
Tabela I - Níveis para os fatores.

[Table I - Factor levels.]

\begin{tabular}{lcccc}
\hline & $\begin{array}{c}\text { A: frita } \\
\text { base }\end{array}$ & $\begin{array}{c}\text { B:\% frita } \\
\text { transp. }\end{array}$ & $\begin{array}{c}\text { C: Tmax. } \\
\text { de queima }\end{array}$ & $\begin{array}{c}\text { D: \% } \\
\text { alumina }\end{array}$ \\
\hline Nível 1 & Frita M & 0 & $1200{ }^{\circ} \mathrm{C}$ & 0 \\
\hline Nível 2 & Frita C & 10 & $1180{ }^{\circ} \mathrm{C}$ & 7 \\
\hline
\end{tabular}

\section{Seleção do arranjo ortogonal}

A seqüência dos experimentos com a combinação dos fatores e níveis é determinada através de um arranjo ortogonal. Este arranjo irá determinar o número de experimentos a serem realizados, assegurando que todos os níveis de todos os fatores serão testados um igual número de vezes. $\mathrm{O}$ arranjo adequado é selecionado de acordo com o número de fatores, níveis e a resolução pretendida. A resolução máxima corresponde ao fatorial completo, onde todos os fatores são testados em cada nível separadamente dos demais fatores. Neste arranjo é avaliada a influência de cada fator isoladamente e de todas as possíveis interações entre os fatores. Um delineamento fatorial completo pode demandar um grande número de experimentos, especialmente para muitos fatores ou muitos níveis de variação. Pode-se, entretanto, selecionar arranjos de menor resolução, onde a influência das interações entre os fatores, se houver, sofrerá sobreposição aos efeitos dos fatores isolados. Nestes, pode-se testar vários fatores com um número de experimentos reduzidos.

Para 4 fatores em dois níveis foi selecionado o arranjo ortogonal L8. Este arranjo apresenta uma resolução média, onde a influência da interação entre alguns fatores pode sofrer sobreposição. O arranjo L8 compreende a execução de oito experimentos, com fatores e interações alocados em sete colunas, conforme Tabela II. Serão utilizadas duas repetições para cada experimento, considerando que cada repetição já representa a média de uma amostra, cujo tamanho foi estabelecido anteriormente na seleção do sistema de medição.

Tabela II - Formato para um arranjo ortogonal L8, com fatores a dois níveis.

[Table II - L8 orthogonal array, with two level factors.]

$\mathrm{n}^{\circ}$

experimento

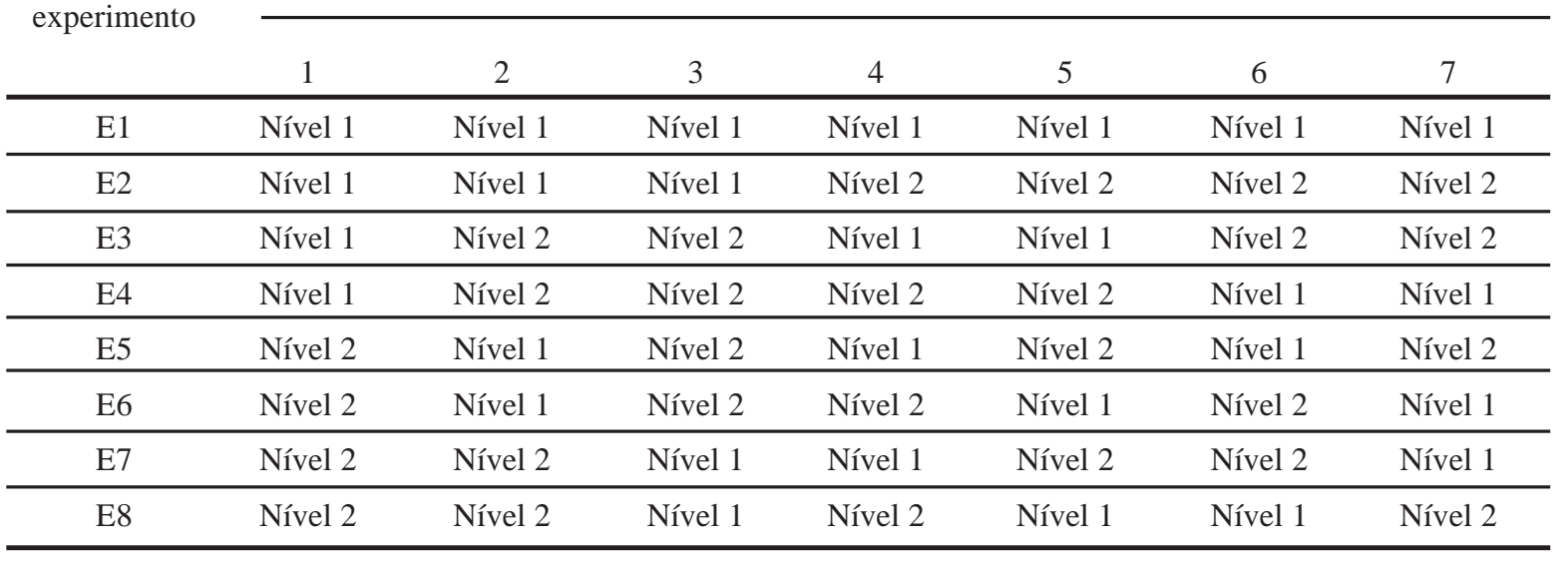

Tabela III - Relação dos experimentos segundo arranjo ortogonal L8.

[Table III - Experimental trials within a L8 orthogonal array.]

\begin{tabular}{|c|c|c|c|c|c|c|c|}
\hline \multicolumn{8}{|c|}{ Fatores e interações } \\
\hline Experimento & AFrita base & $\mathrm{B} \%$ fritas & $\mathrm{AxB}$ & $\mathrm{CT} \max \left({ }^{\circ} \mathrm{C}\right)$ & $\mathrm{AxC}$ & $\mathrm{BxC}$ & $\mathrm{D} \%$ alumina \\
\hline E1 & Frita $\mathrm{M}$ & 0 & Nível 1 & 1200 & Nível 1 & Nível 1 & 0 \\
\hline E2 & Frita M & 0 & Nível 1 & 1180 & Nível 2 & Nível 2 & 7 \\
\hline E3 & Frita M & 10 & Nível 2 & 1200 & Nível 1 & Nível 2 & 7 \\
\hline E4 & Frita M & 10 & Nível 2 & 1180 & Nível 2 & Nível 1 & 0 \\
\hline E5 & Frita $\mathrm{C}$ & 0 & Nível 2 & 1200 & Nível 2 & Nível 1 & 7 \\
\hline E6 & Frita $\mathrm{C}$ & 0 & Nível 2 & 1180 & Nível 1 & Nível 2 & 0 \\
\hline E7 & Frita $\mathrm{C}$ & 10 & Nível 1 & 1200 & Nível 2 & Nível 2 & 0 \\
\hline E8 & Frita C & 10 & Nível 1 & 1180 & Nível 1 & Nível 1 & 7 \\
\hline
\end{tabular}


Seleção das interações de influência.

Sendo quatro fatores alocados em quatro colunas do arranjo L8, restam 3 colunas para alocação das interações. As interações selecionadas com possível influência sobre as características medidas são:

- Frita base x Temperatura de queima (AxC)

- \% frita transparente $\mathrm{x}$ Temperatura de queima $(\mathrm{BxC})$

- Frita base x \% frita transparente (AxB)

As demais interações: Frita base x Adição de alumina, Frita transparente $\mathrm{x}$ Adição de alumina e Temperatura de queima x Adição de alumina foram desconsideradas. A alumina, normalmente, comporta-se como um aditivo inerte e apresenta menor probabilidade de interação com os demais fatores.

\section{Alocação dos fatores e interações.}

Os fatores são alocados nas colunas do arranjo ortogonal e são identificadas as colunas onde serão avaliadas as interações. Os fatores e interações estão alocados conforme a Tabela III. Foram conferidos os códigos E1 a E8, representando as 8 combinações de fatores e níveis para os experimentos.

\section{RESULTADOS E DISCUSSÃO}

\section{Análise dos resultados}

Utilizou-se a observação da influência dos fatores sobre características medidas e, também, sobre as características visuais da superfície. Analisou-se os efeitos por colunas, gráficos de influência e utilizou-se a ferramenta estatística ANOVA (Análise de Variância). O grau de confiança da influência de cada fator foi determinado através do teste F, para os resultados numéricos. A análise dos resultados obtidos está apresentada nos itens seguintes.

\section{Avaliação Visual da Superfície Esmaltada}

As características visuais foram classificadas em: bom, médio, ruim. Esta classificação obedeceu aos seguintes critérios, dependendo da característica avaliada:

Empeno:

- Bom = sem empeno,

- Médio = pouco empeno,

- Ruim = grande empeno.

Aderência:

- Bom = esmalte bem aderido à superfície,

- Médio = esmalte aderido em sua maioria, mas com algum destacamento observado,

- Ruim = esmalte destaca-se facilmente da superfície. Brilho:

- Bom= brilho intenso na superfície esmaltada,

- Médio = leve brilho,

- Ruim = não apresenta brilho.
Textura:

- Bom = superfície lisa e sem defeitos,

- Médio: superfície levemente rugosa,

- Ruim= Superfície apresenta bolhas ou outros defeitos.

A classificação dos esmaltes obtidos em cada experimento está apresentada na Tabela IV. As principais diferenças foram observadas para esmaltes obtidos a partir de diferentes fritas base. Os esmaltes que utilizaram a frita base $\mathrm{M}$ apresentaram maior brilho, textura levemente rugosa e não houve empeno. Os esmaltes que utilizaram a frita base $\mathrm{C}$ apresentaram uma textura lisa, mas sem brilho e houve ocorrência de leve empeno em algumas amostras. Todas as amostras apresentaram uma camada esmaltada opaca, de cor branca, bem aderida à superfície do suporte, sem a ocorrência de destacamentos. Os demais fatores ( $\%$ fritas transparentes, temperatura de queima e \% alumina) não influenciaram de modo significativo as características visuais da superfície esmaltada.

Tabela IV - Avaliação das características visuais da superfície esmaltada.

[Table IV - Analysis of visual characteristics of the glazed surface.]

\begin{tabular}{ccccc}
\hline Experimento & Empeno & Aderência & Brilho & Textura \\
\hline E1 & Bom & Bom & Bom & Médio \\
\hline E2 & Bom & Bom & Médio & Médio \\
\hline E3 & Bom & Bom & Médio & Médio \\
\hline E4 & Bom & Bom & Bom & Médio \\
\hline E5 & Médio & Bom & Ruim & Bom \\
\hline E6 & Médio & Bom & Ruim & Bom \\
\hline E7 & Médio & Bom & Ruim & Bom \\
\hline E8 & Bom & Bom & Ruim & Bom \\
\hline
\end{tabular}

\section{Avaliação das Propriedades Medidas}

Os valores médios obtidos para as características medidas em cada experimento estão apresentados na Tabela V.

A influência de cada fator pode ser avaliada pela diferença entre a soma de todos os valores medidos para o Nível 2 e a soma de todos os valores medidos para o Nível 1. Esta diferença é calculada para cada coluna do arranjo ortogonal e também são calculadas suas variâncias. Quanto maior a variância, maior o efeito do fator correspondente àquela coluna sobre a característica medida. Para se determinar o nível de confiança de se afirmar que um fator influencia esta característica, calculase o valor de F, baseado nas variâncias obtidas. Compara-se, então, com valores tabelados de F, para os graus de liberdade determinados. Quando o valor de F calculado for superior ao valor tabelado para determinado nível de confiança, podemos dizer que afirmação de que o fator influencia a característica medida é verdadeira, com aquele nível de confiança. Desta forma, a tabela 6 apresenta as variâncias e os valores de F calculados para cada fator analisado nos experimentos. 
Tabela V - Avaliação das características medidas para os esmaltes.

[Table V - Evaluation of measured characteristics of the glazed surface.]

\begin{tabular}{ccccc}
\hline Experimento & Porosidade $(\%)$ & Dureza ao Risco $(\mathrm{GPa})$ & Dureza Mohs & Dureza Vickers $(\mathrm{HV})$ \\
\hline E1 & $1,9(\sigma=1,1)$ & $14,99(\sigma=0,25)$ & 5 & $682(\sigma=13)$ \\
\hline E2 & $2,4(\sigma=1,3)$ & $10,18(\sigma=0,99)$ & 6 & $582(\sigma=26)$ \\
\hline E3 & $4,8(\sigma=1,7)$ & $12,59(\sigma=0,53)$ & 6 & $507(\sigma=8)$ \\
\hline E4 & $2,9(\sigma=1,4)$ & $10,70(\sigma=0,22)$ & 6 & $577(\sigma=21)$ \\
\hline E5 & $8,9(\sigma=1,3)$ & $6,73(\sigma=0,08)$ & 5 & $536(\sigma=22)$ \\
\hline E6 & $5,7(\sigma=1,8)$ & $8,19(\sigma=0,32)$ & 6 & $538(\sigma=3)$ \\
\hline E7 & $7,2(\sigma=1,5)$ & $9,43(\sigma=0,31)$ & 7 & -
\end{tabular}

Obs: As amostras E5 e E8 apresentaram uma superfície demasiadamente porosa, dificultando a medida da dureza Vickers.

Fator: frita base

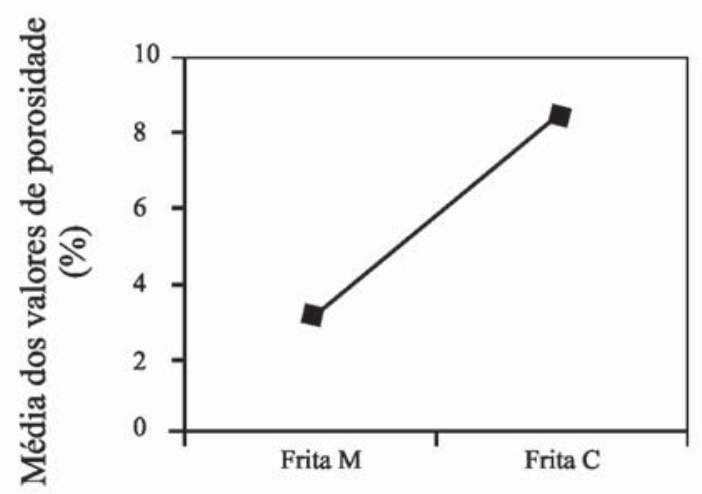

Fator: temperatura de queima

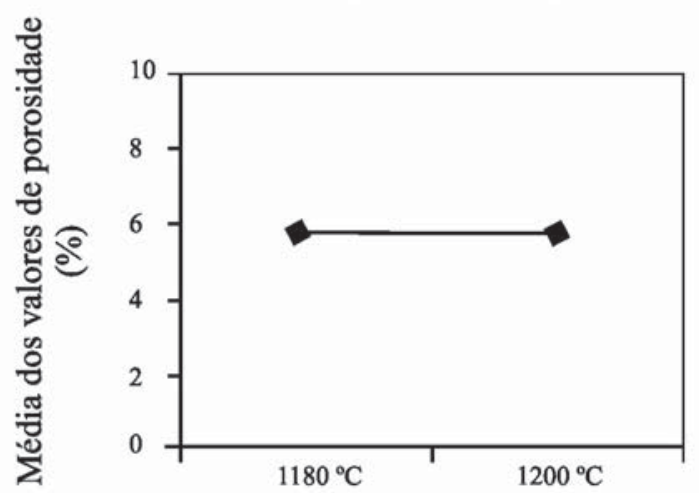

Fator: frita transparente

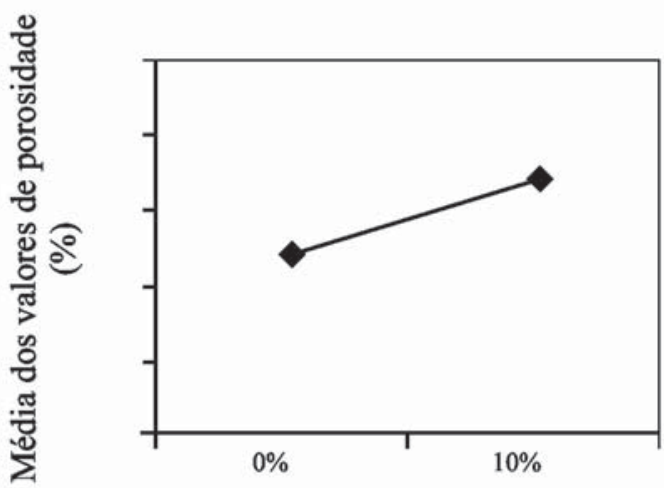

Fator: \% de alumína

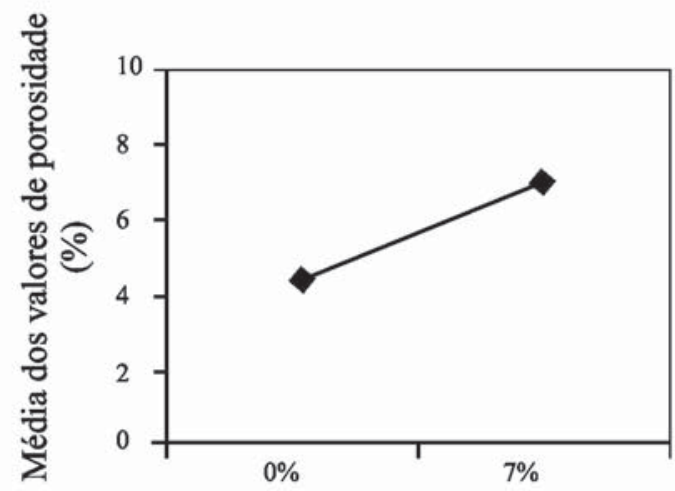

Figura 1: Gráficos de influência dos fatores sobre a porosidade do esmalte.

[Figure 1: Factors influence on glaze porosity.] 
Através do teste F pode-se afirmar com $99 \%$ de confiança que os fatores: frita base, $\%$ frita transparente e $\%$ alumina, influenciam a porosidade. Enquanto tem-se $95 \%$ de confiança que a interação entre os fatores \% frita transparente e temperatura máxima de queima também influenciam a porosidade do esmalte obtido.

Com relação à dureza ao risco, todos os fatores à exceção da \% de frita transparente apresentaram influência sobre a característica medida (nível de confiança $\geq 95 \%$ ).

A influência de cada fator está demonstrada, em valores médios, nos gráficos de influência das Figs 1 e 4, para os fatores: frita base, $\%$ frita transparente, temperatura de queima e \% alumina. A seguir são apresentadas as análises da influência dos fatores sobre cada uma das características medidas.

\section{Influência dos fatores sobre a porosidade}

Como pode ser observado nos gráficos da Fig. 1, os fatores que influenciaram os valores de porosidade são a frita base utilizada, o percentual de frita transparente e o \% alumina na formulação do esmalte. Esmaltes obtidos a partir da frita base $\mathrm{M}$ apresentaram menor porosidade que os esmaltes obtidos a partir da frita base C. Tanto a adição de frita transparente, quanto a adição de alumina, na formulação do esmalte tiveram o efeito de aumentar a porosidade. Era esperado que a adição de uma frita de baixa viscosidade promovesse um maior brilho e uma maior densificação do esmalte, o que não ocorreu. A menor densificação dos esmaltes com adição de frita transparente pode estar relacionada com diferenças na densidade e coeficiente de dilatação desta frita em relação à frita base utilizada. Da mesma forma, estes fatores podem ter resultado no aumento da porosidade observado com a adição de alumina. Variações volumétricas diferentes no resfriamento resultam em separação entre as partículas de composição diferentes e formação de vazios na microestrutura.

O nível de confiança sobre a real influência dos fatores pode ser determinado através das ferramentas estatísticas: Análise de Variância (ANOVA) e aplicação do teste F. Os fatores frita base, \% frita transparente e \% alumina apresentaram um nível de confiança de $99 \%$ a respeito de sua influência sobre a porosidade. Isto é, o risco de afirmar que estes fatores influenciam sobre a porosidade quando eles de fato não exercem influência é de apenas $1 \%$ (risco Alfa). O cálculo da variância e valores de F estão apresentados na Tabela VI. O fator temperatura de queima, isoladamente, não provocou diferenças nos valores de porosidade medidos. Mas foi detectado um efeito significativo das interações alocadas nas colunas 5 e 6 do arranjo ortogonal (Tabela III). Estas interações são 'frita base $\mathrm{x}$ temperatura de queima' e 'frita transparente $\mathrm{x}$ temperatura de queima'. De forma geral, o efeito do aumento da porosidade com a adição de frita transparente foi mais acentuado para a maior temperatura de queima. A frita transparente utilizada é destinada a aplicações cuja queima não excede a temperatura de $1180^{\circ} \mathrm{C}$. Acima desta temperatura pode ocorrer a fervura do esmalte e o aparecimento de bolhas na camada esmaltada, aumentando sua porosidade. De modo inverso, a utilização da frita base $\mathrm{C}$ em maiores temperaturas de queima alcançou porosidade menor do que a mesma formulação queimada na temperatura mais baixa. Isto indica que esta formulação requer maiores temperaturas para que ocorra a diminuição de viscosidade para o espalhamento e densificação adequada da camada esmaltada. Assim sendo, esta formulação não é aplicável sobre os suportes cerâmicos atualmente produzidos para revestimento, que utilizam ciclos de queima dificilmente superiores a $1200{ }^{\circ} \mathrm{C}$.

\section{Influência dos fatores sobre a dureza ao risco}

O ensaio de dureza ao risco, através da técnica esclerométrica, consiste em movimentar, com velocidade constante, a superfície a ser analisada sob um indentador, de geometria definida, gerando um risco cuja largura é medida através de observação em microscópio. A medida da largura é utilizada na determinação da dureza ao risco do material, que para o uso de indentador piramidal é dada através da equação:

$$
H_{r}=K_{g} \frac{F_{n}}{L^{2}}
$$

onde:

$\mathrm{H}_{\mathrm{r}}=$ dureza ao risco $(\mathrm{Pa})$;

$\mathrm{F}_{\mathrm{n}}=$ força normal aplicada $(\mathrm{N})$;

$\mathrm{L}=$ largura do risco $(\mathrm{mm})$;

$\mathrm{K}_{\mathrm{g}}=$ constante geométrica do indentador. Para um indentador Vickers, piramidal, $\mathrm{K}=4$.

No processo de abrasão, a superfície está sujeita ao contato com um complexo de partículas abrasivas, podendo atuar diferentes mecanismos na deformação e remoção do material através de um fenômeno de riscamento múltiplo [6]. A técnica esclerométrica parte do princípio de isolar os efeitos de um contato elementar que risca a superfície, considerando que os efeitos atuantes em cada risco são independentes. Desta forma, permite avaliar quantitativamente a resistência à abrasão de determinado material, através da medida do efeito de uma partícula isolada, com geometria simples, que risca a superfície sob velocidade e carga controladas [7]. Os mecanismos atuantes não dependem somente das condições de riscamento, mas também da natureza do material em contato com o indentador por toda a extensão do risco. Materiais dúcteis tendem a deformar plasticamente à passagem do indentador, enquanto que materiais frágeis sofrem arrancamento de material e trincamento da superfície. Analisando-se a morfologia dos esmaltes testados, não foi observado trincamento até cargas aplicadas próximas a $2 \mathrm{~N}$ (Fig. 2). Entretanto, o aparecimento de trincas pode ser observado quando aplicadas cargas a partir 3N (Fig. 3).

A influência dos fatores com relação à dureza ao risco dos esmaltes testados está apresentada na Fig. 4. Esmaltes obtidos a partir da frita base $\mathrm{M}$ apresentaram maior dureza ao risco do que os esmaltes obtidos a partir da frita base C. Enquanto que os valores de dureza ao risco para os primeiros situaram-se entre 10 e $15 \mathrm{GPa}$, os últimos apresentaram dureza ao risco variando na faixa entre 5 e $10 \mathrm{GPa}$, conforme observado na 


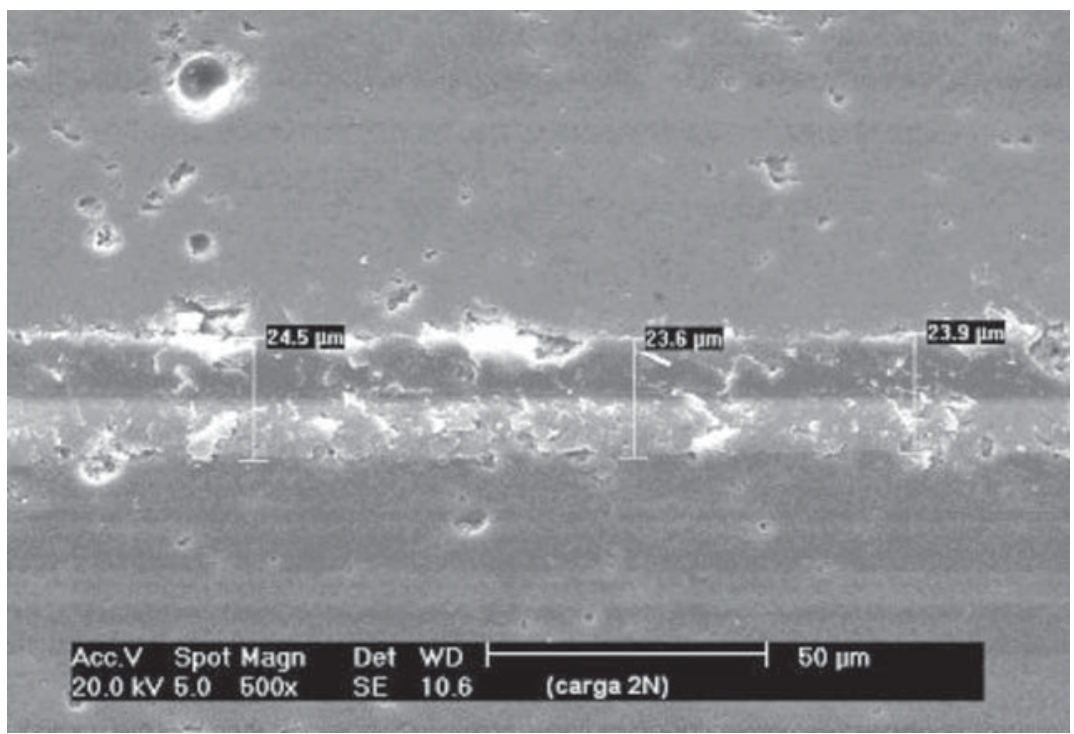

Figura 2: Micrografia do esmalte E1, riscado em esclerômetro, utilizando carga de $2 \mathrm{~N}$. [Figure 2: E1 glaze micrograph, after scratching with a $2 \mathrm{~N}$ load.]

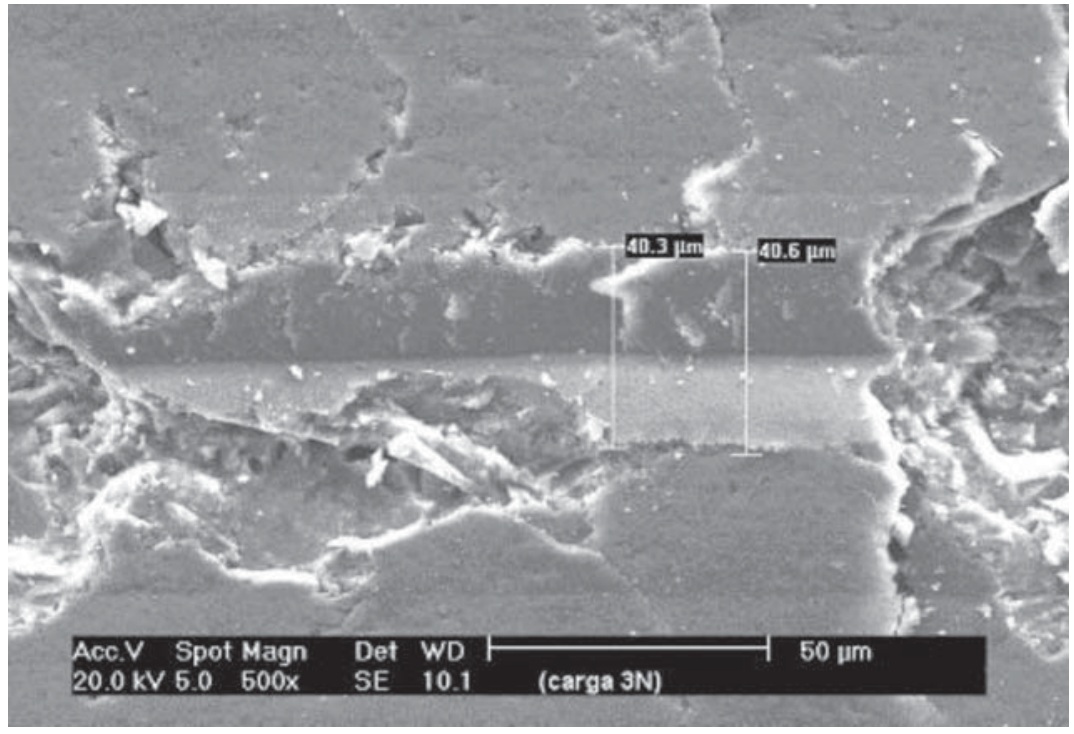

Figura 3: Micrografia do esmalte E2, riscado em esclerômetro, utilizando carga de $3 \mathrm{~N}$. [Figure 3: E2 glaze micrograph, after scratching with a $3 \mathrm{~N}$ load.]

Tabela V. As causas para um melhor desempenho dos esmaltes obtidos a partir da frita $\mathrm{M}$ nos testes de risco estão relacionadas às características microestruturais do esmalte como fases cristalinas de maior dureza e menor porosidade.

Foi observada também a influência dos fatores temperatura de queima e adição de alumina na formulação do esmalte. $\mathrm{O}$ nível de confiança para a influência dos fatores foi determinado em $99 \%$, à exceção da adição de fritas transparentes cuja influência isolada não foi significativa. Maiores temperaturas de queima resultaram em maiores valores de dureza ao risco. Este efeito é atribuído ao favorecimento da cristalização de fases de alta dureza a temperaturas mais altas. A adição de alumina, entretanto, teve o efeito de diminuir a dureza ao risco dos esmaltes. Este efeito da adição de alumina contraria os resultados esperados, sendo esta uma fase de elevada dureza. A diminuição da dureza ao risco é atribuída a maior porosidade resultante da adição de alumina.

As interações entre os fatores também apresentaram efeitos significativos na dureza ao risco. A adição de fritas transparentes na formulação dos esmaltes obtidas a partir da frita $\mathrm{M}$ resultou em ligeira diminuição da dureza ao risco, mas não alterou a dureza dos esmaltes obtidos a partir da frita $\mathrm{C}$. A temperatura de queima também teve efeito mais pronunciado sobre a dureza ao risco dos esmaltes obtidos com a frita base 
Fator: frita base

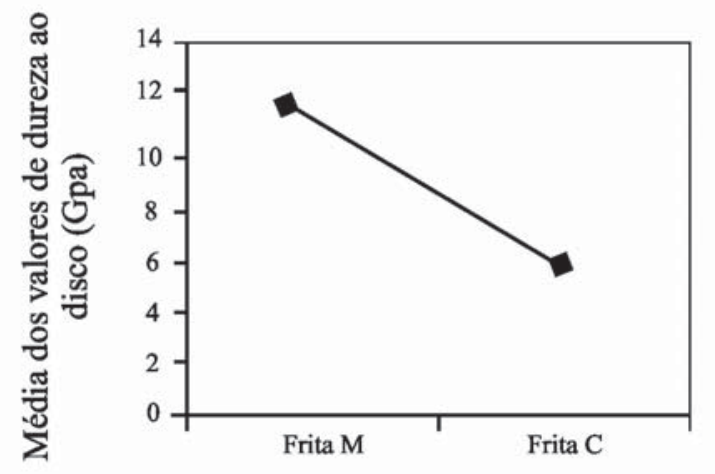

Fator: temperatura de queima

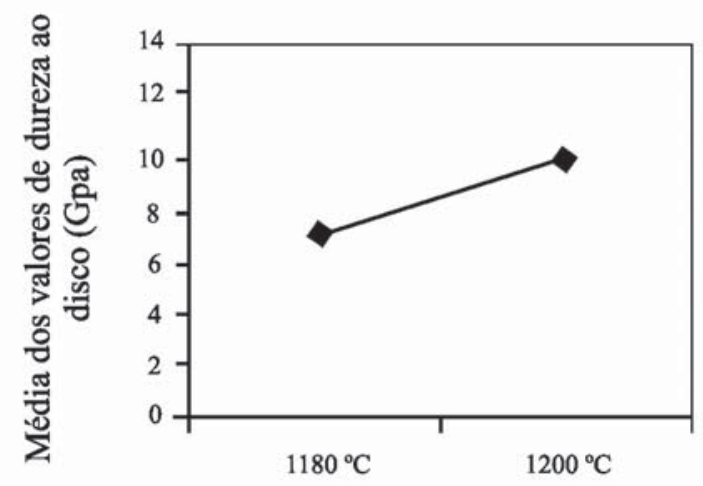

Fator: frita transparente

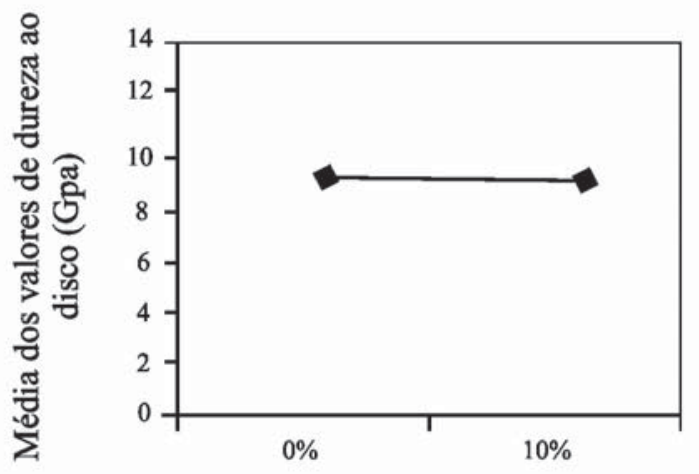

Fator: \% de alumína

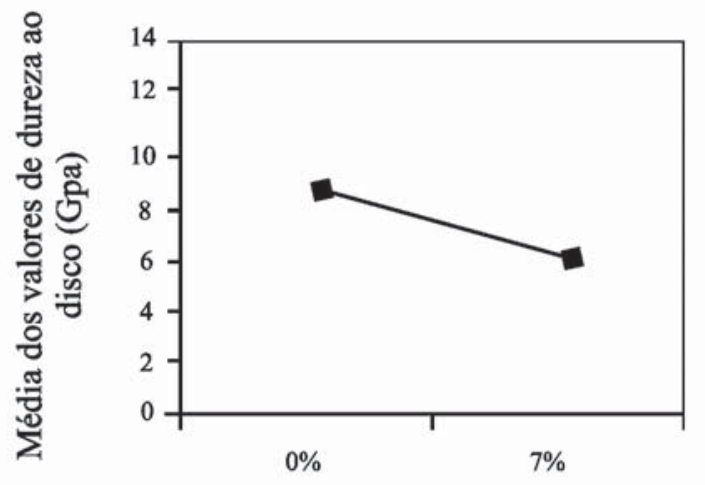

Figura 4: Gráficos de influência dos fatores sobre a dureza ao risco do esmalte. [Figure 4: Factors influence on glaze scratching hardness.]

M do que para os esmaltes obtidos a partir da frita base $\mathrm{C}$.

Considerando os aspectos envolvidos no processo de riscamento, conclui-se que não somente a presença de fases cristalinas de alta dureza no esmalte determina uma alta dureza ao risco do material. Enquanto que a determinação da dureza Vickers depende diretamente da dureza da fase constituinte no ponto de contato com o indentador, a determinação da dureza ao risco consiste em um processo dinâmico, onde as variações da microestrutura ao longo da trajetória do risco combinadas às condições de riscamento irão determinar os mecanismos atuantes na formação do risco. A distribuição das fases cristalinas, a presença de poros e inclusões na microestrutura, portanto, irão influenciar no comportamento do material sujeito ao riscamento e devem ser consideradas na obtenção de esmaltes com elevada dureza ao risco.

\section{Influência dos fatores sobre a dureza Mohs}

Observando-se os dados da Tabela V, percebe-se uma incoerência dos valores de dureza Mohs com relação às demais características medidas. Os esmaltes que apresentaram os maiores valores de dureza ao risco e dureza Vickers não correspondem aos esmaltes com maior dureza Mohs. Tampouco se observou alguma influência significativa dos fatores sobre esta característica. O ensaio de dureza Mohs consiste em riscar a superfície com materiais gradativamente mais duros, na escala Mohs e verificar a partir de que ponto da escala os riscos se tornam visíveis na superfície do material. Esta determinação depende, portanto, de uma avaliação visual e subjetiva, podendo haver grandes variações dependendo da luminosidade do ambiente, refletividade da superfície e, inclusive, da acuidade visual da pessoa que realiza a avaliação. Deste modo, a determinação da dureza Mohs demonstra ser inadequada para uma avaliação quantitativa da resistência à abrasão do material.

\section{Influência dos fatores sobre a dureza Vickers}

Os valores de dureza Vickers apresentados na Tabela V apresentam coerência com os valores de dureza ao risco e demonstram ter sido influenciados de forma semelhante pelos diversos fatores. Os esmaltes obtidos a partir da frita base $\mathrm{M}$ 
Tabela VI - Avaliação da influência dos fatores segundo ANOVA.

[Table VI - Evaluation of factors influence by ANOVA.]

\begin{tabular}{|c|c|c|c|c|c|}
\hline Característica & Fatores & Variância & $\begin{array}{l}\text { Graus de } \\
\text { liberdade }\end{array}$ & $\mathrm{F}$ & $\begin{array}{c}\text { Nível de } \\
\text { confiança }(\%)\end{array}$ \\
\hline \multirow[t]{8}{*}{ Porosidade } & Frita base & 118,59 & 1 & 165,52 & 99 \\
\hline & $\%$ Frita trasparente & 16,24 & 1 & 22,67 & 99 \\
\hline & Frita base $\mathrm{x}$ frita transp. & 0,40 & 1 & 0,55 & - \\
\hline & Temperatura max. & 0,01 & 1 & 0,01 & - \\
\hline & Frita base $\mathrm{x}$ temperatura & 2,22 & 1 & 3,10 & - \\
\hline & Frita transp. $\mathrm{x}$ temperatura & 8,01 & 1 & 11,18 & 95 \\
\hline & $\%$ alumina & 27,35 & 1 & 38,18 & 99 \\
\hline & erro & 0,72 & 8 & - & - \\
\hline \multirow[t]{8}{*}{ Dureza ao risco } & Frita base & 83,12 & 1 & 421,26 & 99 \\
\hline & $\%$ Frita trasparente & 0,56 & 1 & 2,84 & - \\
\hline & Frita base $\mathrm{x}$ frita transp. & 1,28 & 1 & 6,48 & 95 \\
\hline & Temperatura max. & 19,32 & 1 & 97,94 & 99 \\
\hline & Frita base $\mathrm{x}$ temperatura & 5,30 & 1 & 26,88 & 99 \\
\hline & Frita transp. $\mathrm{x}$ temperatura & 1,11 & 1 & 5,60 & 99 \\
\hline & $\%$ alumina & 15,72 & 1 & 79,66 & 95 \\
\hline & erro & 0,20 & 1 & - & 99 \\
\hline
\end{tabular}

(E1 a E4) apresentaram maior dureza Vickers que os esmaltes obtidos a partir da frita base C (E6 e E7). Também a maior temperatura de queima utilizada nos experimentos E1 e E3 favoreceu uma maior dureza dos esmaltes obtidos. Esta influência atribui-se à maior formação de fases cristalinas de alta dureza nos esmaltes obtidos a partir da frita base $\mathrm{M}$ e queimados a temperaturas maiores. Não foi possível realizar a análise da soma dos efeitos dos fatores em diferentes níveis devido a ausência de valores de dureza Vickers para os experimentos E5 e E8.

\section{CONCLUSÕES}

A utilização de um arranjo ortogonal por Taguchi auxiliou na escolha dos fatores e parâmetros dos testes de aplicação, definiu a seqüência de experimentos realizados e as propriedades medidas. Após a realização dos experimentos foi possível identificar a influência dos fatores sobre as características medidas e identificar a formulação e os parâmetros que conferiram os melhores resultados quanto à aplicação pretendida para o esmalte. Os esmaltes obtidos a partir da frita base $\mathrm{M}$ apresentaram maior dureza e menor porosidade do que os esmaltes obtidos a partir da frita base C. Observou-se que a adição de frita transparente e alumina na formulação do esmalte aumentaram a porosidade e diminuíram a dureza, enquanto que uma maior temperatura de queima favoreceu uma maior dureza do esmalte e não influenciou a porosidade.

A utilização de um arranjo L8 para quatro fatores a dois níveis reduziu o número de experimentos que seriam necessários no caso de um arranjo fatorial completo, ao desprezar os efeitos de algumas interações entre os fatores. A quantificação dos efeitos por colunas permite avaliar estatisticamente e determinar o grau de confiança da influência dos fatores, através da Análise de Variância e o teste F. A utilização de grandezas como a porosidade, a dureza ao risco e a dureza Vickers possibilitou uma avaliação quantitativa para a seleção do esmalte com melhores características para a aplicação pretendida.

A partir dos resultados obtidos, é possível ainda otmizar a determinação dos parâmetros mais adequados à obtenção do esmalte, através do refinamento da investigação. Seleciona-se, assim, menos fatores e mais níveis, com variação restrita às faixas consideradas adequadas nesta primeira investigação.

\section{AGRADECIMENTOS}

Os autores agradecem a ESMALGLASS pela disponibilização de infra-estrutura e pessoal para os testes de aplicação dos esmaltes e ao CNPq pelo apoio financeiro. 


\section{REFERÊNCIAS}

[1] S. Mei, J. Yang, J. M. F. Ferreira, R. Martins, Mater. Sci. Eng. A 334 (2002) 11.

[2] P. J. Ross, Taguchi Techniques for Quality Engineering, McGraw-Hill, S. Paulo (1996).

[3] C. Lira, A. P. N. Oliveira, O. Alarcon, Glass Tech. 42, 3 (2001) 91.

[4] C. Lira, Oliveira, A. P. N., Alarcon, O. "Sintering and crystallisation of $\mathrm{MgO}-\mathrm{Al}_{2} \mathrm{O}_{3}-\mathrm{SiO}_{2}$ glass powders and obtaining of cordierite glass-ceramic compositions", Glass Tech. 45, 1 (2004) 43.
[5] ABNT - Associação Brasileira de Normas Técnicas. Placas cerâmicas para revestimento - Especificação e métodos de ensaios: NBR 13818, Rio de Janeiro (1997).

[6] R. E. F. Q. Nogueira, J. D. B. Mello, Abrasão do Quartzo: um estudo esclerométrico, Anais do $8^{\circ} \mathrm{CBECIMAT,} \mathrm{Campinas,}$ SP (1988) 451.

[7] O. Alarcon, W. Weingaertner, H. Roman, F. Sousa, M. Pereira, A. Spiller, D. Tridapalli, Design and development of an apparatus to measure the scratch hardness of ceramic floor tiles, in: Qualicer 2004, Castellón, Espanha 2 (2004) PGI283 - PGI-295.

(Rec. 21/10/03, Rev. 13/04/04, Ac. 15/10/04) 